\title{
Biological method in monitoring small rivers of the Oka River basin
}

\author{
Tatyana Guseva ${ }^{1, *}$, Iyri Mazhayskiy ${ }^{2}$ \\ ${ }^{1}$ FSBEI HE Ryazan Medical University named after I.P. Pavlov, Ministry of Health of Russia, \\ Ryazan, Russia \\ ${ }^{2}$ Meshcherskiy branch of the National Scientific Research Institute of Hydraulic Engineering and \\ Amelioration named after A.N. Kostyakov, Ryazan, Russia
}

\begin{abstract}
The Oka basin is characterized by serious environmental problems associated with the depletion of water resources. Communities of aquatic organisms are the first to respond to negative changes in the aquatic environment, such communities are used as indicators in biological monitoring. The aim of the work was to assess the ecological state of the small river of the Oka basin by bioindication. The quality of the water in the reservoir was assessed by chemical indicators - biogenic and technogenic elements. The saprobity index of the reservoir was determined by the species diversity of periphyton. The results revealed technogenic and organic pollution of the small river. According to the results of biological monitoring, the value of the saprobity index is 2.85 , which corresponds to class 4 of the reservoir quality, and the water is assessed as polluted. Monitoring the degree of pollution of the small river by the biodiversity of the periphyton community allows you to determine the degree of water pollution quickly.
\end{abstract}

Keywords: small river, biogenic elements, heavy metals, saprobity, periphyton.

The Oka basin is characterized by intensive development of the territory, and as a result, the accumulation of environmental problems associated with the depletion of water resources. A significant negative effect on water bodies is exerted by runoff from agrolandscapes containing both biogenic elements and heavy metals $[4,5,7]$. Anthropogenic impacts on water bodies are multifactorial in nature, which makes it difficult to assess the quality of the aquatic environment only by abiotic parameters. Currently, environmental researchers have universally recognized and legally supported the simultaneous use of chemical analysis, bioindication, and biotesting methods for an objective assessment of the ecological state of water bodies [15, 16]. The community of hydrobionts, which can act as biological indicators, is the first to respond to all negative changes in the parameters of the aquatic environment. Biological monitoring of water bodies has a number of significant

\footnotetext{
* Corresponding author: guseva.tm@yandex.ru
} 
advantages, since indicator organisms respond to relatively weak anthropogenic pressures that are recorded without the use of time-consuming and expensive methods $[2,3,8,10,11$, 12 , 13]. In world practice, a large number of monitoring methods, including various characteristics of groups of aquatic organisms, are used. Biological control methods are various: determining the species diversity of aquatic organisms from microorganisms to ichthyofauna, assessing the saprobity of a reservoir, using phytoplankton, zooplankton, benthos, periphyton and higher aquatic vegetation as indicators. Bio-indicator organisms should be ubiquitous in the researched area and have a well-defined reaction to ongoing changes in the environment. Based on many years of research, certain types of hydrobionts bioindicators, capable of living in water of varying degrees of pollution are identified. In practice, a chemical analysis of surface water is usually carried out. But, having determined the composition of aquatic organisms, it is possible to obtain the most important environmental information: not only to assess the state of the environment, but also to predict the development of the aquatic ecosystem as a whole $[1,6,9,17,18,19,20]$.

The purpose of work: to assess the ecological status of the small river of the Oka basin by bioindication.

To achieve the goal, the following tasks:

-to assess the water quality of the small river of the Oka basin by chemical characteristics;

-to conduct biological monitoring of the reservoir (to assess the species diversity of aquatic organisms, to determine their belonging to the saprobity zone by the importance of indicator species).

The research was carried out at an ecological testing ground located on the territory of the Meshchera lowland, including landscapes on the left bank of the Oka River basin. Ecopolygon is a natural model that includes the water-collecting area of a small river, where ameliorated landscapes are located on. This water body receives runoffs from irrigated, drained territories, arable land, pastures and also summer cottages, that is, almost all types of use of agrolandscapes that can have a negative impact on the aquatic ecosystem are presented here. Over a long period of time, the chemical indicators of the aquatic environment and the determination of biogenic and technogenic pollution were monitored at the ecological polygon. Chemical analysis of water was carried out according to generally accepted methods: ammonium nitrogen, nitrates, nitrites - by photometry [GOST 33045-2014], heavy metals - by adsorption spectrometry [GOST R 57162-2016]. The periphyton organisms as the most typical communities represented by attached organisms are the most indicative to assess the water quality of small reservoirs using the biological method. The samples were collected with a scraper. The periphyton was microscoped, noting the frequency of occurrence of indicator organisms. The saprobity index was calculated according to the Pantle-Bucca method in the modification of Sladchek V. [GOST 17.1.3.07-82]. The indicator significance and the saprobity zone were determined for each type of periphyton according to the lists of organisms "Unified methods for the water quality research".

The number of individuals found in the sample was evaluated using a 5-point system: 1 point - single specimens, 2 points - few ( 2 - 4 individuals), 3 points - average number ( 5 - 7 individuals), 4 points - many $(8-11$ individuals), 5 points - in the mass (from 12 individuals). The saprobity index (Ind $S$ ) was calculated by the formula:

$$
\text { Ind } S=\Sigma(S h) / \Sigma h
$$

where: $S$ is the indicator significance of individual species, $h$ is the relative number of individuals of the species.

The object of the research is a small river directly connected with the water system of the Oka river. Its main characteristics: length $-6.4 \mathrm{~km}$, water-collecting area $-30.0 \mathrm{~km}^{2}$, average width $-1.0 \mathrm{~m}$, average depth $-0.4 \mathrm{~m}$, maximum water flow rate $-0.3 \mathrm{~m}^{3} / \mathrm{s}$. The 
water of the small river belongs to the calcium hydrocarbonate class, transparent, without color and odor, $\mathrm{pH}$ is $6.5-7.0$, hardness is 1.2-2.5 mg-equ / 1 , the amount of dissolved $\mathrm{O}_{2}$ is $6.9-7.4 \mathrm{mg} / 1$. The studied water body for a considerable period of time experiences anthropogenic stress as a result of the functioning of the irrigation system, artificial drainage, the presence of summer cottages, and private lands on the model landscape. A water body is a collector that receives both surface and subsurface runoff from the landscape, that affects the hydrochemical characteristics of the reservoir. The results of long-term monitoring of biogenic and technogenic pollution of a water body are presented in table 1 .

Table 1. Hydrochemical characteristics of the small river (long-term average indicators, $\mathrm{mg} / \mathrm{l}$ ).

\begin{tabular}{|c|c|c|}
\hline Indicator & Value (long-term average) & $\begin{array}{c}\text { Maximum allowable concentration } \\
\left(\mathrm{MAC}_{\mathrm{f}}{ }^{*}\right.\end{array}$ \\
\hline $\mathrm{NH}_{4}{ }^{+}$ & 1,2 & 0,5 \\
\hline $\mathrm{NO}_{3}{ }^{-}$ & 1,5 & 40,0 \\
\hline $\mathrm{NO}_{2}{ }^{-}$ & 0,01 & 0,08 \\
\hline $\mathrm{Cu}$ & 0,003 & 0,001 \\
\hline $\mathrm{Zn}$ & 0,017 & 0,01 \\
\hline $\mathrm{Pb}$ & 0,012 & 0,006 \\
\hline $\mathrm{Cd}$ & 0,001 & 0,005 \\
\hline
\end{tabular}

* $\mathrm{MAC}_{\mathrm{f}}$ - maximum allowable concentration for water in commercial fishery reservoirs (in accordance with the order of the Ministry of Agriculture of Russia of October 12, 2018 N 454).

To assess the negative impact of pollutants specifically on aquatic organisms, the longterm average values of the considered parameters were compared with the $\mathrm{MAC}_{\mathrm{f}}$. The content of nitrogen compounds in water did not exceed the permissible values, with the exception of $\mathrm{NH}_{4}{ }_{4}$, which is explained by the action of runoffs coming mainly from the lands allocated for summer cottages. The concentration of $\mathrm{Cd}$ is in the range of $\mathrm{MAC}_{\mathrm{f}}$, and the content of $\mathrm{Pb}, \mathrm{Cu}$, and $\mathrm{Zn}$ in some cases exceeded this indicator. The results of chemical assessment of water indicate the existing technogenic pressure, as well as organic pollution, which worsens the ecological condition of the reservoir and creates unfavorable conditions for the aquatic ecosystem.

One of the informative indicators of the anthropogenic load on aquatic ecosystems is the qualitative composition of hydrobionts, undergoing significant changes under the influence of pollutants. In order to determine the species diversity of the biota of the researched water body, the periphyton samples were taken to determine the saprobity index of the small river (Table 2).

Table 2. Dominant species of periphyton of the small river.

\begin{tabular}{|c|c|c|c|}
\hline Organisms & Saprobity Zone, S & Species frequency, $\mathrm{h}$ & Sh \\
\hline \multicolumn{4}{|c|}{ Seaweed } \\
\hline Scenedesmus acuminatus & 2 & 1 & 2 \\
\hline Spirogyra sygmoide & 2 & 2 & 4 \\
\hline Closterium acerosum & 3 & 4 & 12 \\
\hline Cyclotella menengiata & 3 & 2 & 6 \\
\hline Navicula viridua & 3 & 3 & 9 \\
\hline Navicula cryptocephala & 3 & 2 & 6 \\
\hline Navicula rhynchocephala & 3 & 5 & 15 \\
\hline Nitzschia sigmoidea & 2 & 3 & 6 \\
\hline $\begin{array}{lll}\begin{array}{l}\text { Navicula } \\
\text { capitata }\end{array} & \text { hungarica } & \\
\end{array}$ & 2 & 3 & 6 \\
\hline & & $\sum \mathrm{h}=\mathbf{2 5}$ & $\sum \mathrm{Sh}=66$ \\
\hline
\end{tabular}




\begin{tabular}{|l|c|c|c|}
\hline \multicolumn{3}{|c|}{ Protozoa } & 16 \\
\hline Euglena viridis & 4 & 4 & 9 \\
\hline Chilidonella cuculata & 3 & 3 & 6 \\
\hline Colpoda cuculus & 3 & 2 & $\sum \mathrm{Sh}=\mathbf{3 1}$ \\
\hline \multicolumn{2}{|l|}{} & $\sum \mathrm{h}=\mathbf{9}$ & $\sum \mathrm{Sh}=\mathbf{9 7}$ \\
\hline
\end{tabular}

The results of microscopy of periphyton representatives: seeweed - 9 species, protozoa 3 species. Comparison of tabular data with a list of saprobity indicator organisms has shown that most of the hydrobionts found in a water body belong to $\alpha, \beta$ - mesosaprobes, and polysaprobes are also found. Based on the results of biological monitoring, the saprobity index was calculated: Ind $S=97 / 34=2.85$. This value corresponds to class 4 of the quality of the reservoir, and water is assessed as polluted. The depletion of the species composition of hydrobionts of the researched reservoir is an adequate indicator of its pollution.

Thus, controlling the degree of pollution of a small river by the biodiversity of the periphyton community helps to quickly establish its state and determine the degree of pollution. The biological method, and in particular the saprobiological analysis, by the ratio of indicator organisms allows you to assess the ecological situation of the aquatic ecosystem quickly and without additional costs.

\section{References}

1. E. Yu. Afonina, A.V. Afonin Assessment of the status of hydrobiocenoses of small watercourses in the Argun river basin, Theor. and appl. ecol., 3, 57 (2017)

2. T.Ya. Ashikhmina, N.M. Alalykina, L.I. Domracheva Biological monitoring of natural-technogenic systems (Publishing House of Komi Scientific Center Ural Branch of the Russian Academy of Sciences, Syktyvkar, 2011)

3. E.A. Bronovitskaya, V.V. Petrash, T. Ya. Ashikhmina, L.V. Kondakova Comparative toxicity assessment of surface water and soil based on the results of biotesting by two independent laboratories, Theor. and appl. ecol., 4, 59 (2015)

4. R.G. Dzhamalov, A.M. Nikanorov, O.S. Reshetnyak, T.I. Safronova Waters of the Oka basin: chemical composition and sources of pollution, Wat. and Ecol.: Probl. and Sol., 3, 114 (2017)

5. Report on the state and environmental protection in the Ryazan region in 2018. (Ryazan, 2019).

6. I.E. Dubovik, M.Yu. Sharipova Land and water epiphytic cyanoprokaryotes and seeweed and the possibility of their use in assessing the state of the environment, Theor. and appl. ecol., 1, 51 (2016)

7. Yu.A. Mazhayskiy, T.M. Guseva Monitoring of heavy metals in the ecosystem of the small river of the Oka basin, Theor. and appl. ecol., 2, 54 (2017)

8. G.G. Matishov, S.V. Kreneva, V.M. Muraveyko, I.A. Shparkovskiy, G.V. Ilyin Biotesting and prediction of variability of water ecosystems in conditions of anthropogenic pollution (KNC RAN, Apatity , 2003)

9. E.V. Makhanova Diagnosis of the ecological state of a reservoir: a comparison of the results of chemical analysis, biotesting and bioindication, Wat. and Ecol.: Probl. and Sol., 2 (78), 102 (2019)

10. O.P. Melekhova, E.I. Sarapultseva Biological environmental control: bioindication and biotesting (Academy, Moscow, 2010)

11. E.E. Minchionok, N.A. Pakhomova Assessment of the state of urban aquatic ecosystems by hydrobiological indicators, Theor. and appl. ecol., 3, 48 (2016) 
12. A.S. Olkova Modern trends in the development of the methodology of biotesting of aquatic environments, Theor. and appl. ecol., 3, 19 (2018)

13. A.S. Olkova Actual directions of development of the methodology of biotesting of aquatic environments, Wat. and Ecol.: Probl. and Sol., 2 (74), 40 (2018)

14. A.S. Olkova, E.V. Makhanova Selection of biotests for environmental studies of waters polluted with mineral forms of nitrogen, Wat. and Ecol.: Probl. and Sol., 4 (76),70 (2018)

15. Electronic fund of legal and scientific and technical documentation (2020). RD 52.24.3092016. Organization and conduct of regime monitoring of the state and pollution of surface water of land [online] Available at: http://docs.cntd.ru/document/495872993

16. The electronic fund of legal and scientific and technical documentation (2020). Water Code of the Russian Federation (as amended on April 24, 2020) [online] Available at: http://docs.cntd.ru/document/901982862

17. W. Brack, S. Ait-Aissa, R.M. Burgess Effect-directed analysis supporting monitoring of aquatic environments. An in-depth overview, Scien. of The Total Environ., 544, 1073 (2016)

18. A. Cattaneo, G. Methot, B. Pinel-Alloul, T. Niyonsenga \& L. Lapierre Epiphyte size and taxonomy as biological indicators of ecological and toxicological factors in Lake St.-Francois (Quebec), Environ. Pollut., 87, 357 (1995)

19. J.M. O'Connell, E.D. Reavie, J.P. Smol Assemblent of water quality using epiphytic diatom assemblages on Cladophora from the St. Lawrence river (Canada), Diat. Resear., 12, 55 (1997)

20. A.G. Solimini, R. Ptacnik, A.C. Cardoso Towards holistic assessment of the functioning of ecosystems under the Water Framework Directive, TrAC Trend. in Analyt. Chem., 28, 143 (2009) 